\title{
Primary Definitive Hemostasis for Traumatic Massive Hemoperitoneum With Hemodynamic Instability Improves Outcomes: A Single-Center, Propensity Score-Matched Analysis
}

Masaki Matsuda ( $\sim$ godfather5522@gmail.com )

Department of Emergency and Critical Care Medicine, Saitama Medical Center, Saitama Medical University

Makoto Sawano

Department of Emergency and Critical Care Medicine, Saitama Medical Center, Saitama Medical University

\section{Research Article}

Keywords: Damage control, Definitive hemostasis, Hemoperitoneum, Propensity score

Posted Date: January 21st, 2022

DOI: https://doi.org/10.21203/rs.3.rs-1271339/v1

License: (c) (1) This work is licensed under a Creative Commons Attribution 4.0 International License.

Read Full License 


\section{Abstract}

\section{Background}

Currently, damage control laparotomy (DCL) is a standard operative approach for traumatic massive hemoperitoneum with hemodynamic instability. However, we have often observed unsatisfactory hemostatic effects of DCL for severe abdominal traumas, requiring definitive hemostasis (DH). We hypothesized that primary $\mathrm{DH}$ could improve the outcomes of hemodynamically unstable patients with traumatic massive hemoperitoneum compared with DCL.

\section{Methods}

This retrospective, single-center, observational study evaluated hemodynamically unstable patients with traumatic massive hemoperitoneum requiring surgical intervention between 2005 and 2020. The patient population was divided into two groups: a DH group and a DCL group. Propensity score matching was used to adjust for differences in baseline characteristics in the two groups, a one-to-one matched analysis using nearest-neighbor matching was performed based on the estimated propensity score of each group. The primary outcome was in-hospital mortality, and secondary outcomes were 48-hour mortality and 28-day mortality.

\section{Results}

A total of 170 patients met the inclusion criteria; 141 patients underwent primary $\mathrm{DH}$, and 29 underwent DCL. In the propensity-matched analysis with 27 pairs, the DH group had significantly lower in-hospital mortality (odds ratio [OR] $0.154 ; 95 \%$ confidence interval $(\mathrm{Cl}) 0.035$ to 0.682 ) and 28-day mortality (OR $0.200 ; 95 \% \mathrm{Cl} 0.044$ to 0.913 ) than the $\mathrm{DCL}$ group, but the 48-hour mortality did not differ significantly between the two groups (25.9\% vs. $44.4 \%$; OR 0.375 ; $95 \%$ Cl $0.099-1.414)$.

\section{Conclusions}

Primary $\mathrm{DH}$ is an effective surgical procedure for traumatic massive hemoperitoneum with hemodynamic instability. Primary DH can be the standard surgical intervention for severe abdominal trauma.

\section{Introduction}

Currently, damage control laparotomy (DCL) is a standard operative approach for traumatic massive hemoperitoneum with hemodynamic instability. Rotondo et al. reported the usefulness of DCL (1), followed by a series of similar reports (2-6). They emphasized that expeditious hemostasis was paramount to prevent trauma-induced coagulopathy $(7,8)$. We also frequently performed DCL to rescue moribund victims, but we often observed unsatisfactory hemostatic effects of $D C L$ for severe abdominal trauma, requiring definitive hemostasis (DH). 
On the other hand, with the establishment of damage control resuscitation (DCR) for severe trauma, we can avoid trauma-induced coagulopathy by preemptive massive transfusion, limiting crystalloid, and adequate supplementation of some coagulation factor concentrates (9) Thus, intensive care focused on trauma-induced coagulopathy has made it possible to perform relatively long-time surgery, and the need for DCL has been decreased. As a result, we gradually shifted the surgical strategy for severe abdominal trauma from $\mathrm{DCL}$ to mandatory primary $\mathrm{DH}$.

We hypothesized that primary $\mathrm{DH}$ could potentially improve the outcomes of traumatic massive hemoperitoneum with hemodynamic instability compared with DCL.

\section{Materials And Methods}

Study design

The Institutional Review Board of Saitama Medical University approved this study protocol. A retrospective, observational study of patients who underwent urgent laparotomy for massive hemoperitoneum with hemodynamic instability at a level I trauma center in Japan between January 2005 and December 2020 was conducted. From a prospective trauma database maintained by the Department of Emergency and Critical Care Medicine, the data were reviewed to obtain age, sex, mechanism of injury, Glasgow coma scale (GCS) score, systolic blood pressure (SBP), heart rate (HR), Injury Severity Score (ISS), head/neck, chest, abdomen, and extremity Abbreviated Injury Scale (AIS) score, dominant sources of hemorrhage, and surgical procedures.

Inclusion and exclusion criteria

Trauma patients who underwent surgical intervention for massive hemoperitoneum with hemodynamic instability were included. Hemodynamic instability was defined as an SBP of $90 \mathrm{mmHg}$ or lower before surgical intervention. Patients with prehospital cardiac arrest who could not be resuscitated despite surgical intervention were excluded.

Operative procedure

The selection of surgical procedure was based on the physicians' clinical judgment. DCL was defined as any surgical procedure that resulted in temporary abdominal closure or abdominal packing, and $\mathrm{DH}$ was defined as completed definitive hemostasis. Based on the surgical procedure, patients were classified as either undergoing primary $\mathrm{DH}$ (DH group) or DCL (DCL group).

\section{Outcomes}

The primary outcome was in-hospital mortality, and the secondary outcomes were 48-hour mortality and 28-day mortality.

Statistical analysis 
Patients in the $\mathrm{DH}$ and $\mathrm{DCL}$ groups were then matched 1:1 based on their propensity scores, using the nearest neighbor method and a caliper width of 0.2 standard deviations for the propensity score. Age, GCS, SBP, ISS, and dominant sources of hemorrhage (hepatic injury without inferior vena cava [IVC] injury, hepatic injury with IVC injury, great vessel injury, splenic injury, pancreas injury, and mesenteric injury) were selected as potential confounders and entered in the model. In the descriptive statistics, numeric or ordered variables are presented as medians and interquartile ranges, and categorical variables are shown as counts and percentages. Significance was defined as a p value of less than 0.05 or was assessed with $95 \%$ confidence intervals in all statistical analyses. Medians and ranges of continuous data were compared using the Mann-Whitney $U$ test. Categorical data were compared using Pearson's chi-squared test or Fisher's exact test as appropriate. In the propensity score-matched analysis, we compared the outcomes between the two groups, using conditional logistic regression analyses. Data were analyzed using SPSS software, version 24 (IBM Corp., Armonk, NY).

\section{Results}

After the exclusion of ineligible patients, 170 eligible patients were divided into the $\mathrm{DH}$ group $(n=141)$ and the $\mathrm{DCL}$ group ( $\mathrm{n}=29)$ (Fig. 1). By one-to-one propensity score matching, 27 pairs from the $\mathrm{DH}$ and $\mathrm{DCL}$ groups were selected. The C-statistic for goodness of fit was 0.810 in the propensity score model.

Table 1 shows the demographics and Table 2 shows the dominant sources of hemorrhage of all patients $(n=170)$ and of the propensity score-matched patients $(n=54)$. Table 3 shows the surgical procedures in the DH group. In all patients, the median GCS score, ISS, the proportion of patients with a high AIS (>3) of the chest and extremities, hepatic injury with IVC injury, splenic injury, great vessel injury, and mesenteric injury were significantly different between the two groups. After propensity score matching, patient distributions were closely balanced between the $\mathrm{DH}$ and $\mathrm{DCL}$ groups.

The in-hospital mortality rate of the entire cohort was $27.6 \%(47 / 170)$, the 48 -hour mortality rate was $14.7 \%$ (25/170), and the 28-day mortality rate was $21.2 \%$ (36/170). Table 2 shows in-hospital mortality (primary outcome), 48-hour mortality, and 28-day mortality (secondary outcomes), cause of death in the DH and DCL groups. In the analysis of all patients, in-hospital, 48-day mortality, and 28-day mortality were significantly lower in the DH group than in the DCL group. The propensity score-matched analysis showed significant differences between the DH and DCL groups in in-hospital mortality (33.3\% vs. $74.1 \%$; odds ratio [OR] $0.154 ; 95 \%$ confidence interval [CI] 0.035-0.682) and 28-day mortality (29.6\% vs. 59.3\%; HR $0.200 ; 95 \% \mathrm{Cl} 0.044-0.913)$. But the 48-hour mortality did not differ significantly between the two groups (25.9\% vs. $44.4 \%$; OR $0.375 ; 95 \% \mathrm{Cl} 0.099-1.414)$. The one-year survival curves showed higher survival in the $\mathrm{DH}$ group (log-rank $\mathrm{p}=0.002$ ) (Fig. 2).

\section{Discussion}

The results of this study showed that primary $\mathrm{DH}$ for traumatic massive hemoperitoneum with hemodynamic instability improved a long-term mortality compared with DCL. Supporting this concept are 
the data from Harvin et al. showing that DCL was associated with increased mortality (10). Although Harvin et al. focused on the patients requiring emergent laparotomy for all severe abdominal trauma, the present study may be the first to focus on traumatic massive hemoperitoneum with hemodynamic instability, which most likely leads to DCL.

There were many possible explanations as to why primary DH improved a long-term outcome. First, primary DH needs only one-time surgery. Patients with severe abdominal injury often have severe concomitant injuries. In particular, a severe brain injury and orthopedic injuries including spinal, pelvic and femoral fractures require both early surgical intervention and multidisciplinary management. A severe head injury requires the head-up position. Early definitive fixations for spinal, pelvic, and femoral fractures are always necessary for early mobilization to prevent pneumonia and venous thromboembolism. Although DCL with an open abdomen and re-operations interfere with the management of these concomitant injuries, primary $\mathrm{DH}$ requiring only one-time surgery can allow us to dedicate subsequent management to concomitant injuries. The present data of all patients showed that the mortality rate of brain injury, sepsis, or multiple organ injury was low. Second, hepato-biliarypancreatic (HBP) surgery has evolved over the decades. Traumatic massive hemoperitoneum is often caused by HBP injuries; therefore, an HBP surgical procedure is often necessary. Currently, establishment of surgical procedures and development of energy devices, surgical staplers, and electrocautery have made hepatectomy and pancreatectomy technically easier and faster. Finally, DCR has evolved and become well known. DCR aims at preventing or reversing coagulopathy through permissive hypotension, limiting crystalloids, and delivering higher ratios of plasma and platelets. Thus, the implementation of DCR allowed us to perform DH requiring a prolonged surgical procedure. In absolute terms, DH potentially has a greater hemostatic effect than DCL.

The present in-hospital, 48-hour mortality, and 28-day mortality rates of all patients (including cardiac arrest on admission) were $27.6 \%, 14.7 \%$, and $21.2 \%$, respectively. In 2002 , Clarke et al. published data from 1986 to 1999 reporting a mortality rate of $40 \%$ for hypotensive trauma patients undergoing laparotomy within 90 minutes of arrival (7). In 2017, Harvin et al. reported that the mortality rate of hypotensive trauma patients undergoing emergent laparotomy was $46 \%$ (11). In 2020, Traynor et al. reported that the in-hospital mortality rate of patients who underwent DCL in high-income countries was $29 \%$ (12). Even though these studies excluded patients with cardiac arrest on admission or intra-operative death, the present outcomes including patients with cardiac arrest or intra-operative death were superior to these reports. The present data were satisfactory compared with these other reports, affirming our surgical strategy based on mandatory $\mathrm{DH}$.

The aim of DCL is to avoid the lethal triad that is described as the metabolic derangement of hypothermia, coagulopathy, and metabolic acidosis (6). The tenet that the lethal triad leads to a "vicious, bloody cycle" and subsequent irreversible physiological exhaustion is emphasized far too much in abdominal trauma surgery. When the concept of "Damage Control" was first described in 1983 (13), HBP surgery was still a high-risk procedure, and DCR had not yet been established. At that time, expeditious hemostasis with abdominal packing was the only optimal procedure to avoid the lethal triad. However, 
with current development of HBP surgery and established DCR, DCL is no longer required. Higa et al. reported improved mortality and no abdominal compartment syndrome in severe abdominal trauma requiring laparotomy, despite a decrease in the rate of $\mathrm{DCL}$ at three years, and they pointed out the overuse of DCL (14).

This study has several limitations. First, the small sample size and single-center design limit the power and generalizability of the present findings. Second, although propensity scores were used to balance the groups' characteristics, there could be some other unmeasurable confounders and potential bias. Finally, the short-term outcome might be largely affected by the attending surgeons. Since there was no clear-cut indication for $\mathrm{DCL}$, attending surgeons had to select the optimal procedures based on each patient's clinical status, severity of the injured organ, and concomitant injuries. Therefore, multi-institutional, prospective, observational studies will be useful in resolving these limitations and remaining questions.

\section{Conclusion}

Primary DH is an effective surgical procedure for traumatic massive hemoperitoneum with hemodynamic instability. Primary DH can be the standard surgical intervention for severe abdominal trauma.

\section{Abbreviations}

AIS Abbreviated injury score

$\mathrm{Cl}$ Confidence interval

DCL Damage control laparotomy

DCR Damage control resuscitation

DH Definitive hemostasis

GCS Glasgow Coma Scale

HBP Hepato-biliary-pancreas

ISS Injury severity score

IVC Inferior vena cava

OR Odds ratio

SBP Systolic blood pressure

\section{Declarations}




\section{Authors' contributions}

MM conceived and designed the study. MM participated in writing, MS was responsible for statistical analysis. All authors read and approved the final manuscript.

\section{Funding}

No funding

\section{Availability of data and materials}

Not applicable

\section{Ethics approval and consent to participate}

The Institutional Review Board of Saitama Medical University approved this study protocol.

\section{Consent for publication}

Not applicable

\section{Competing interests}

All authors declare that they have no competing interests.

\section{Author details}

Department of Emergency and Critical Care Medicine, Saitama Medical Center, Saitama Medical University, 1981 Kamoda, Kawagoe-shi, Saitama-ken, 350-8550, Japan

\section{References}

1. Rotondo MF, Schwab CW, McGonigal MD, Phillips GR, 3rd, Fruchterman TM, Kauder DR, et al. 'Damage control': an approach for improved survival in exsanguinating penetrating abdominal injury. The Journal of trauma. 1993;35(3):375-82; discussion 82-3.

2. Moore EE, Burch JM, Franciose RJ, Offner PJ, Biffl WL. Staged physiologic restoration and damage control surgery. World journal of surgery. 1998;22(12):1184-90; discussion 90-1.

3. Parr MJ, Alabdi T. Damage control surgery and intensive care. Injury. 2004;35(7):713-22.

4. Sugrue M, D'Amours SK, Joshipura M. Damage control surgery and the abdomen. Injury. 2004;35(7):642-8.

5. Germanos S, Gourgiotis S, Villias C, Bertucci M, Dimopoulos N, Salemis N. Damage control surgery in the abdomen: an approach for the management of severe injured patients. Int J Surg. 2008;6(3):24652.

6. Jaunoo SS, Harji DP. Damage control surgery. Int J Surg. 2009;7(2):110-3. 
7. Clarke JR, Trooskin SZ, Doshi PJ, Greenwald L, Mode CJ. Time to laparotomy for intra-abdominal bleeding from trauma does affect survival for delays up to 90 minutes. The Journal of trauma. 2002;52(3):420-5.

8. Barbosa RR, Rowell SE, Fox EE, Holcomb JB, Bulger EM, Phelan HA, et al. Increasing time to operation is associated with decreased survival in patients with a positive FAST examination requiring emergent laparotomy. The journal of trauma and acute care surgery. 2013;75(1 Suppl 1):S48-52.

9. Cannon JW, Khan MA, Raja AS, Cohen MJ, Como JJ, Cotton BA, et al. Damage control resuscitation in patients with severe traumatic hemorrhage: A practice management guideline from the Eastern Association for the Surgery of Trauma. The journal of trauma and acute care surgery. 2017;82(3):605-17.

10. Harvin JA, Wray CJ, Steward J, Lawless RA, McNutt MK, Love JD, et al. Control the damage: morbidity and mortality after emergent trauma laparotomy. Am J Surg. 2016;212(1):34-9.

11. Harvin JA, Maxim T, Inaba K, Martinez-Aguilar MA, King DR, Choudhry AJ, et al. Mortality after emergent trauma laparotomy: A multicenter, retrospective study. The journal of trauma and acute care surgery. 2017;83(3):464-8.

12. Traynor MD, Jr., Hernandez MC, Aho JM, Wise K, Kong V, Clarke D, et al. Damage Control Laparotomy: High-Volume Centers Display Similar Mortality Rates Despite Differences in Country Income Level. World journal of surgery. 2020;44(12):3993-8.

13. Stone HH, Strom PR, Mullins RJ. Management of the major coagulopathy with onset during laparotomy. Annals of surgery. 1983;197(5):532-5.

14. Higa G, Friese R, O'Keeffe T, Wynne J, Bowlby P, Ziemba M, et al. Damage control laparotomy: a vital tool once overused. The Journal of trauma. 2010;69(1):53-9.

\section{Tables}

Table 1. Demographic Characteristics of the DH and DCL groups 


\begin{tabular}{|c|c|c|c|c|c|c|}
\hline & \multicolumn{3}{|c|}{ Before matching } & \multicolumn{3}{|c|}{ After matching } \\
\hline & $\begin{array}{l}\text { DH } \\
\text { group }\end{array}$ & $\begin{array}{l}\text { DCL } \\
\text { group }\end{array}$ & $\begin{array}{l}P \\
\text { value }\end{array}$ & $\begin{array}{l}\text { DH } \\
\text { group }\end{array}$ & $\begin{array}{l}\text { DCL } \\
\text { group }\end{array}$ & $\begin{array}{l}\mathrm{P} \\
\text { value }\end{array}$ \\
\hline Patients, n & 141 & 29 & & 27 & 27 & \\
\hline Age, y, median (IQR) & $\begin{array}{l}44(22- \\
61)\end{array}$ & $\begin{array}{l}51(30- \\
68)\end{array}$ & 0.224 & $\begin{array}{l}49 \\
(25.5- \\
63)\end{array}$ & $\begin{array}{l}49(27.5- \\
65.5)\end{array}$ & 0.797 \\
\hline Male, n (\%) & $\begin{array}{l}109 \\
(77.3)\end{array}$ & $\begin{array}{l}18 \\
(62.1)\end{array}$ & 0.130 & $\begin{array}{l}20 \\
(74.1)\end{array}$ & $16(59.3)$ & 0.248 \\
\hline Penetrating injury, n (\%) & $12(8.5)$ & $2(6.9)$ & 0.773 & $4(14.8)$ & $2(7.41)$ & 0.386 \\
\hline $\begin{array}{l}\text { Glasgow Coma Scale score, } \\
\text { median (IQR) }\end{array}$ & $\begin{array}{l}14(12- \\
15)\end{array}$ & $\begin{array}{l}9(3- \\
13)\end{array}$ & 0.000 & $\begin{array}{l}12(3- \\
14)\end{array}$ & $9(3-12.5)$ & 0.445 \\
\hline $\begin{array}{l}\text { Systolic blood pressure (mmHg), } \\
\text { median (IQR) }\end{array}$ & $\begin{array}{l}84(70- \\
100)\end{array}$ & $\begin{array}{l}80(53- \\
90)\end{array}$ & 0.051 & $\begin{array}{l}79(60- \\
97.5)\end{array}$ & $\begin{array}{l}77(46.5- \\
88)\end{array}$ & 0.228 \\
\hline Injury severity score, median (IQR) & $\begin{array}{l}29(21- \\
42)\end{array}$ & $\begin{array}{l}38(33- \\
45)\end{array}$ & 0.004 & $\begin{array}{l}35 \\
(25.5- \\
45)\end{array}$ & $\begin{array}{l}38(31.5- \\
45)\end{array}$ & 0.739 \\
\hline \multicolumn{7}{|l|}{ AIS, n (\%) } \\
\hline AIS head/neck>3 & $\begin{array}{l}17 \\
(12.1)\end{array}$ & $2(6.9)$ & 0.422 & $4(14.8)$ & $2(7.41)$ & 0.386 \\
\hline AIS chest>3 & $\begin{array}{l}31 \\
(22.0)\end{array}$ & $\begin{array}{l}13 \\
(44.8)\end{array}$ & 0.001 & $8(29.6)$ & $11(40.7)$ & 0.393 \\
\hline AIS abdomen>3 & $\begin{array}{l}116 \\
(82.2)\end{array}$ & $\begin{array}{l}26 \\
(89.7)\end{array}$ & 0.329 & $\begin{array}{l}23 \\
(85.2)\end{array}$ & $25(92.6)$ & 0.386 \\
\hline AIS extremity $>3$ & $6(4.3)$ & $\begin{array}{l}4 \\
(13.8)\end{array}$ & 0.047 & $2(7.4)$ & $4(14.8)$ & 0.386 \\
\hline
\end{tabular}

AIS Abbreviated Injury Scale, DCL Damage Control Surgery, DH Definitive Hemostasis, IQR Interquartile range

Table 2. Dominant sources of hemorrhage of the DH and DCL group 


\begin{tabular}{|c|c|c|c|c|c|c|}
\hline & \multicolumn{3}{|c|}{ Before matching } & \multicolumn{3}{|c|}{ After matching } \\
\hline & $\begin{array}{l}\mathrm{DH} \\
\text { group }\end{array}$ & $\begin{array}{l}\text { DCL } \\
\text { group }\end{array}$ & $\begin{array}{l}P \\
\text { value }\end{array}$ & $\begin{array}{l}\mathrm{DH} \\
\text { group }\end{array}$ & $\begin{array}{l}\mathrm{DCL} \\
\text { group }\end{array}$ & $\begin{array}{l}\mathrm{P} \\
\text { value }\end{array}$ \\
\hline & $n=141$ & $n=29$ & & $n=27$ & $n=27$ & \\
\hline Hepatic injury, n (\%) & $\begin{array}{l}54 \\
(38.3)\end{array}$ & $19(65.5)$ & 0.007 & $\begin{array}{l}18 \\
(66.6)\end{array}$ & $19(70.4)$ & 0.770 \\
\hline $\begin{array}{l}\text { without juxta-hepatic venous } \\
\text { injury }\end{array}$ & $\begin{array}{l}46 \\
(32.6)\end{array}$ & $13(44.8)$ & 0.209 & $\begin{array}{l}14 \\
(51.9)\end{array}$ & $13(48.1)$ & 0.785 \\
\hline $\begin{array}{l}\text { with juxta-hepatic venous } \\
\text { injury }\end{array}$ & $8(5.7)$ & $6(20.7)$ & 0.007 & $4(14.8)$ & $6(22.2)$ & 0.484 \\
\hline Splenic injury, n (\%) & $\begin{array}{l}46 \\
(32.6)\end{array}$ & $3(10.3)$ & 0.016 & $3(11.1)$ & $3(11.1)$ & 1.000 \\
\hline Great vessel injury, $\mathrm{n}(\%)$ & $3(2.1)$ & $3(10.3)$ & 0.029 & $3(11.1)$ & $1(3.7)$ & 0.299 \\
\hline Pancreas injury, n (\%) & $7(5.0)$ & $2(6.9)$ & 0.672 & $2(7.4)$ & $2(7.4)$ & 1.000 \\
\hline mesenteric injury, n (\%) & $\begin{array}{l}29 \\
(20.6)\end{array}$ & $2(6.9)$ & 0.083 & $1(3.7)$ & $2(7.4)$ & 0.552 \\
\hline
\end{tabular}

DCL Damage Control Surgery, DH Definitive Hemostasis

Table 3. Surgical procedures of the DH group

\begin{tabular}{|lll|}
\hline & $\begin{array}{l}\text { Before matching } \\
\mathrm{n}=141\end{array}$ & $\begin{array}{l}\text { After matching } \\
\mathrm{n}=27\end{array}$ \\
\hline Hepatectomy, $\mathrm{n}(\%)$ & $28(19.8)$ & $7(25.9)$ \\
\hline IVC repair, $\mathrm{n}(\%)$ & $10(7.1)$ & $6(22.2)$ \\
\hline Hepatorrhaphy, $\mathrm{n}(\%)$ & $16(11.3)$ & $5(18.5)$ \\
\hline Splenectomy, $\mathrm{n}(\%)$ & $32(22.7)$ & $3(11.1)$ \\
\hline Distal pancreatectomy, $\mathrm{n}(\%)$ & $10(7.1)$ & $2(7.4)$ \\
\hline Aortic repair, $\mathrm{n}(\%)$ & $1(0.71)$ & $1(3.7)$ \\
\hline bowel and mesenteric repair, $\mathrm{n}(\%)$ & $30(21.3)$ & $1(3.7)$ \\
\hline Splenorrhaphy, $\mathrm{n}(\%)$ & $4(2.8)$ & 0 \\
\hline Partial splenectomy, $\mathrm{n}(\%)$ & $3(2.1)$ & 0 \\
\hline Pancreatico-duodenectomy, $\mathrm{n}(\%)$ & $2(1.4)$ & 0 \\
\hline Others, $\mathrm{n}(\%)$ & $5(3.5)$ & $2(7.4)$ \\
\hline
\end{tabular}


Table 4. Outcomes of DH and DCL groups

\begin{tabular}{|c|c|c|c|c|c|c|c|c|}
\hline & \multicolumn{4}{|c|}{ Before matching } & \multicolumn{4}{|c|}{ After matching } \\
\hline & $\begin{array}{l}\text { DH } \\
\text { group }\end{array}$ & $\begin{array}{l}\text { DCL } \\
\text { group }\end{array}$ & OR & $95 \% \mathrm{Cl}$ & $\begin{array}{l}\text { DH } \\
\text { group }\end{array}$ & $\begin{array}{l}\text { DCL } \\
\text { group }\end{array}$ & $O R^{*}$ & $\begin{array}{l}95 \% \\
\mathrm{Cl}^{*}\end{array}$ \\
\hline & $n=141$ & $\mathrm{n}=29$ & & & $n=27$ & $\mathrm{n}=27$ & & \\
\hline $\begin{array}{l}\text { In-hospital mortality, } \\
\text { n (\%) }\end{array}$ & $\begin{array}{l}26 \\
(18.1)\end{array}$ & $\begin{array}{l}21 \\
(72.4)\end{array}$ & 0.086 & $\begin{array}{l}0.034- \\
0.216\end{array}$ & $\begin{array}{l}9 \\
(33.3)\end{array}$ & $\begin{array}{l}20 \\
(74.1)\end{array}$ & 0.154 & $\begin{array}{l}0.035- \\
0.682\end{array}$ \\
\hline $\begin{array}{l}\text { 48-hour mortality, } \mathrm{n} \\
\text { (\%) }\end{array}$ & $\begin{array}{l}12 \\
(8.5)\end{array}$ & $\begin{array}{l}13 \\
(44.8)\end{array}$ & 0.114 & $\begin{array}{l}0.045- \\
0.293\end{array}$ & $\begin{array}{l}7 \\
(25.9)\end{array}$ & $\begin{array}{l}12 \\
(44.4)\end{array}$ & 0.375 & $\begin{array}{l}0.099- \\
1.414\end{array}$ \\
\hline $\begin{array}{l}\text { 28-day mortality, } n \\
(\%)\end{array}$ & $\begin{array}{l}19 \\
(13.5)\end{array}$ & $\begin{array}{l}17 \\
(58.6)\end{array}$ & 0.110 & $\begin{array}{l}0.045- \\
0.266\end{array}$ & $\begin{array}{l}8 \\
(29.6)\end{array}$ & $\begin{array}{l}16 \\
(59.3)\end{array}$ & 0.200 & $\begin{array}{l}0.044- \\
0.913\end{array}$ \\
\hline \multicolumn{9}{|l|}{$\begin{array}{l}\text { Cause of death, } n \\
(\%)\end{array}$} \\
\hline $\begin{array}{l}\text { Uncontrollable } \\
\text { hemorrhage }\end{array}$ & $\begin{array}{l}11 \\
(7.8)\end{array}$ & $\begin{array}{l}17 \\
(58.6)\end{array}$ & 0.060 & $\begin{array}{l}0.023- \\
0.156\end{array}$ & $\begin{array}{l}6 \\
(22.2)\end{array}$ & $\begin{array}{l}16 \\
(59.3)\end{array}$ & 0.167 & $\begin{array}{l}0.037- \\
0.745\end{array}$ \\
\hline $\begin{array}{l}\text { Multiple organ } \\
\text { failure }\end{array}$ & $4(2.8)$ & $2(6.9)$ & 0.394 & $\begin{array}{l}0.069- \\
2.261\end{array}$ & $\begin{array}{l}3 \\
(11.1)\end{array}$ & $2(7.4)$ & 1.500 & $\begin{array}{l}0.251- \\
8.977\end{array}$ \\
\hline $\begin{array}{l}\text { Traumatic brain } \\
\text { injury }\end{array}$ & $5(3.5)$ & $2(6.9)$ & 0.496 & $\begin{array}{l}0.091- \\
2.693\end{array}$ & 0 & $2(7.4)$ & 0.015 & $\begin{array}{l}0.000- \\
1327\end{array}$ \\
\hline Sepsis & $2(1.4)$ & 0 & & & 0 & 0 & & \\
\hline
\end{tabular}

Cl Confidence Interval, DCL Damage Control Surgery, DH Definitive Hemostasis, OR Odds Ratio $* \mathrm{OR}$ and $95 \% \mathrm{Cl}$ were calculated using by conditional logistic regression analyses

\section{Figures}




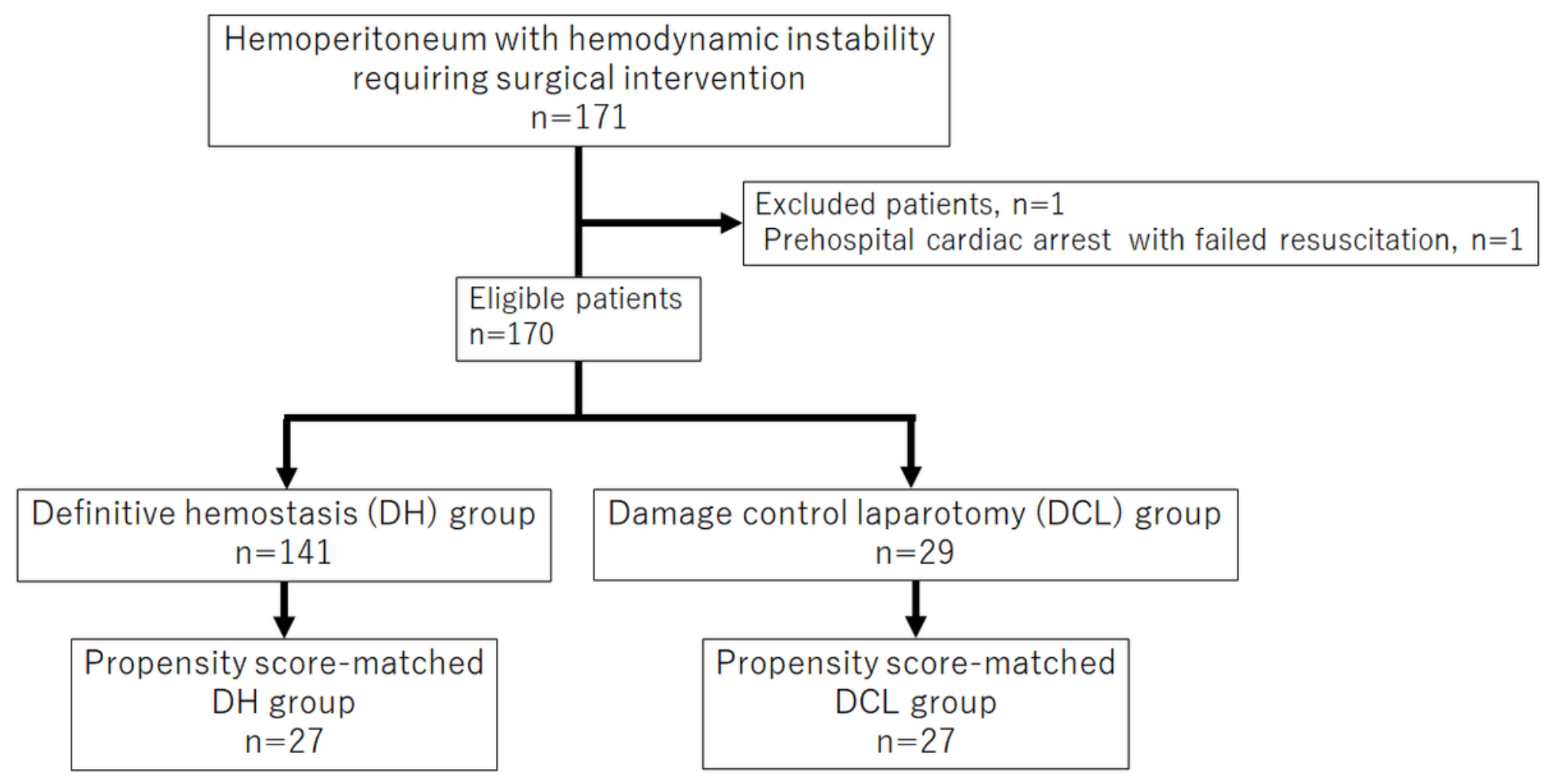

\section{Figure 1}

Flow chart of hemodynamically unstable patients with traumatic hemoperitoneum requiring surgical intervention and propensity score matching of patients who underwent $\mathrm{DH}$ and $\mathrm{DCL}$ 


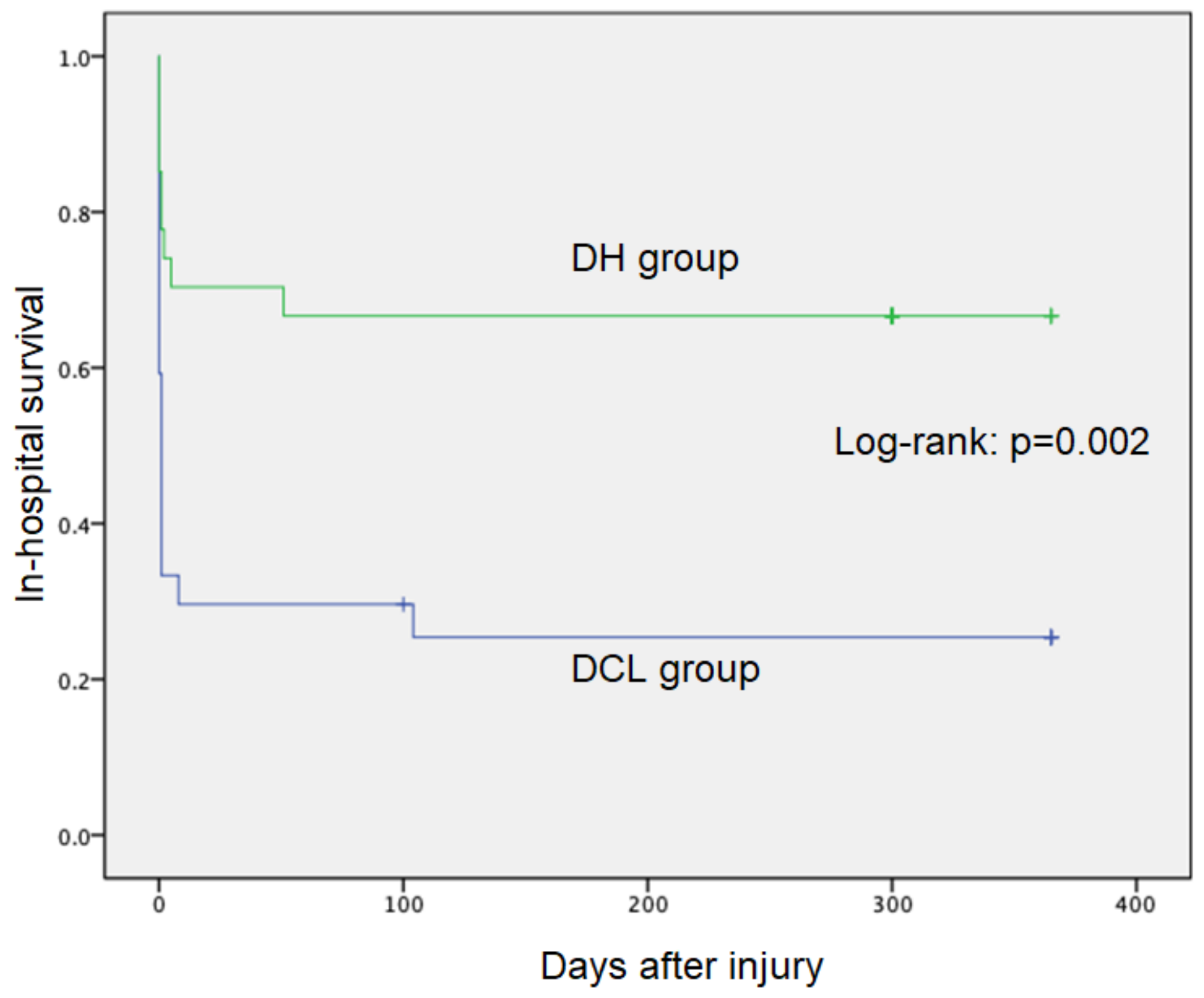

Figure 2

Kaplan-Meier estimation of in-hospital survival in propensity score-matched DH and DCL groups. The P value was generated with the use of a log-rank test. 